(С Ю.Н. Егорова, Ю.А. Генварева, Т.А. Зотова, И.А. Наличникова DOI: http://doi.org/10.15350/2409-7616.2020.2.17

УДК 378

\author{
ПРОФЕССИОНАЛЬНАЯ САМОРЕАЛИЗАЦИЯ СТУДЕНТА ВУЗА: \\ ОСОБЕННОСТИ, ФАКТОРЫ, УСЛОВИЯ \\ Ю.Н. Егорова, Ю.А. Генварева, Т.А. Зотова, И.А. Наличникова
}

Егорова Юлия Николаевна, доктор педагогических наук, профессор, заведующий кафедрой «Общеобразовательные дисциплины», Оренбургский институт путей сообщения, филиал ФГБОУ ВО «Самарский государственный университет путей сообщения», Оренбург, Россия. SPIN-код: 8815-9166 E-mail: egorova333@rambler.ru

Генварева Юлия Анатольевна, кандидат педагогических наук, доцент кафедры «Общеобразовательные дисциплины», Оренбургский институт путей сообщения, филиал ФГБОУ ВО «Самарский государственный университет путей сообщения», Оренбург, Россия. SPIN-код: 7326-6785 E-mail: genvar@mail.ru

Зотова Татьяна Александровна, кандидат педагогических наук, доцент кафедры «Общеобразовательные дисциплины», Оренбургский институт путей сообщения, филиал ФГБОУ ВО «Самарский государственный университет путей сообщения», Оренбург, Россия. E-mail: mansi80@mail.ru

Наличникова Инна Анатольевна, кандидат филологических наук, доцент кафедры «Общеобразовательные дисциплины», Оренбургский институт путей сообщения, филиал ФГБОУ ВО «Самарский государственный университет путей сообщения», Оренбург, Россия.

SPIN-код: 3422-3186

E-mail: nal-inna@yandex.ru

Аннотация. В статье рассматриваются основные условия, которые необходимо создать в высшем техническом учебном заведении для формирования успешной профессиональной самореализации $\kappa$ будущей профессиональной деятельности 6 транспортных организациях в качестве инженеров путей сообщения. Особое внимание авторами уделяет многоаспектности и многогранности учебного прочесса и созданию необходимой образовательной среды для успешного обучения инженера путей сообщения. В статье отмечается важность роли информаџионного и учебно- 
методического обеспечения учебного прочесса и его составляющие. Авторы акиентируют внимание на предъявляемые требования к научно-педагогическому составу высшего технического учебного заведения. В статье поднимается вопрос об условиях эффрективного осуществления профессиональной деятельности. Проведен теоретический анализ проблемь перехода личности $к$ саморазвитию и самореализации, в отношении которой был адаптирован и уточнен соответствующий понятийный аппарат. Обсуждаются особенности самореализачии в различных видах профессиональной деятельности, определяются факторы самореализации. Обращено внимание на взаимодействие между преподавателями и обучаемыми в рамках образовательной деятельности. Авторы уделяют внимание роли контроля и анализа оценок полученных результатов преподавания и возможности корректировки учебного процесса на основе полученных данных. Исследование самореализачии во многих сферах позволяет объединить достижения общей психологии, психологии личности, а также достижения психологической практики и предложить уровневую модель профессиональной самореализации. Результать проведенного исследования могут быть использовань профессорско-преподавательским составом железнодорожных вузов с целью совершенствования процесса профессиональной подготовки инженеров путей сообщения.

Ключевые слова: самореализачия, профессиональная самореализащия, образовательный прочесс, инженер путей сообщения.

\section{PROFESSIONAL SELF-REALIZATION OF A UNIVERSITY STUDENT: FEATURES, FACTORS, CONDITIONS}

Y.N. Egorova, Y.A. Genvareva, T.A. Zotova, I. A. Nalichnikova

Yuliya N. Egorova,

Doctor of pedagogical sciences, professor, acting. Dean, head of the department "General education disciplines", Orenburg Institute of Railways, branch of "Samara State Transport University", Orenburg, Russian Federation. E-mail: egorova333@rambler.ru

Yuliya A. Genvareva, Candidate of pedagogical sciences associate professor of the department "General education disciplines",

Orenburg Institute of Railways, branch of "Samara State Transport University", Orenburg, Russian Federation.

E-mail: genvar@mail.ru

Tatyana A. Zotova, Candidate of pedagogical sciences associate professor of the department "General education disciplines",

Orenburg Institute of Railways, branch of "Samara State Transport University", Orenburg, Russian Federation.

E-mail: mansi80@mail.ru

Inna A. Nalichnikova, 
Candidate of Philology, associate professor of the department "General education disciplines", Orenburg Institute of Railways, branch of "Samara State Transport University", Orenburg, Russian Federation. E-mail: nal-inna@yandex.ru

\begin{abstract}
The article describes the basic conditions that need to be created in a higher technical educational institution to form successful professional self-realization of students in the future professional activity in transport organizations as engineers of communicational ways. The authors pay special attention to the multidimensional and multifaceted learning process and the creation of the necessary educational environment for the successful training of the engineer of communicational ways. The work notes the importance of the role of information and educationalmethodological support of the educational process and its components. The authors emphasize the requirements for the scientific and pedagogical composition of the higher technical educational institution. The question is raised about conditions for the effective implemention of professional activities. A theoretical analysis of the problem of the individuals transition to self-development and self-realization was carried out, in attitude of which the corresponding conceptual apparatus was adapted and refined. Features of self-realization in different types of professional activity are discussed, factors of self-realization are determined. Attention is drawn to the interaction between teachers and trainees within the framework of educational activities. The authors pay attention to the role of monitoring and analyzing estimates of the results of teaching and the possibility of adjusting the educational process on the basis of the data obtained. The self-realization research in many spheres allows to unite achievements of the general psychology, psychology of the personality and also achievement of psychological practice and to offer-level model of professional selfrealization. The results of the study can be used by the faculty of railway universities to improve the process of professional training of engineers of communicational ways.
\end{abstract}

Keywords: self-realization, professional self-realization, educational process, engineer of a railway university.

Железнодорожный комплекс занимает важное стратегическое значение в России. Реформа железнодорожной структуры направлена на обеспечение социальноэкономического развития страны, улучшение качества транспортного обслуживания пользователей, повышение эффективности перевозок и инвестиционной привлекательности российских железных дорог. В связи с этим, отрасль заинтересована в высококачественных инженерах, владеющих современными технологиями. Новые кадры должны быть ориентированы на работу в современных условиях, осуществлять исследования проблемной ситуации и находить технически грамотные решения. Вузы, в свою очередь обязаны учитывать потребности производства, принципиально изменять образ специалиста, взгляд на способы его подготовки. Таким образом возрастает необходимость обеспечения образовательного процесса новым, более полным, личностно- и профессиональноинтегрированным результатом. Педагогическое сопровождение профессиональной самореализации студента железнодорожного вуза обусловлено требованиями Профессиональных стандартов железнодорожного транспорта.

Научные труды российских ученых А.К. Марковой, Л.М. Митиной, В.А. Сластёнина подтверждают, что не востребованность в профессии порождает неудовлетворенность ею, а это, в свою очередь, отрицательно сказывается и на учебно-профессиональном процессе. 3.С.Белова в своем исследовании отмечает, что «выбирая профессию, молодые люди выбирают свой жизненный путь, добровольно подчиняя себя правилам и требованиям 
избранной профессии. Выбирают себя в этой профессии, ибо только от самого человека зависит, насколько он готов освоить будущую профессию, работать по-новому, сотворить и создавать в избранной сфере новое, ценное и необходимое для общества» [1].

Самореализация студента в образовательном процессе университета основывается на понимании того, что преподаватели и студенты не разнонаправленные полюса, они коллективный субъект познания, применения знаний, производства знаний, становления личности как студента, так и преподавателя. В данном контексте нам импонирует точка зрения В.Н. Кормаковой, которая в качестве новой профессионально-педагогической практики предлагает тьюторство. По мнению автора, тьюторство способствует индивидуализации образования, создает благоприятные возможности для индивидуализации процесса профессиональной подготовки, учебно-профессиональной самореализации студентов в вузе. Для реализации педагогического сопровождения ученая использует коучинг-технологию. Основными формами педагогического сопровождения учебнопрофессиональной самореализации студентов при реализации технологии коучинга в вузе являются групповые и индивидуальные консультации. Необходим поиск новых педагогических форм взаимодействия, соответствующих современным требованиям и запросам обучающихся. Одной из таких форм становится тьюторское сопровождение. Основной характеристикой которого выступает длительная, продолжительная работа тьютора или педагога-тьютера с обучающимися. В данном случае необходимо отметить роль тьютора. Тьютора одновременно может выступать организатором взаимодействия, быть партером, наставником, консультантом [2].

Современная молодежь стремится максимально полно реализовать свой личностный потенциал. В настоящее время в обществе все более востребованным становится человек, умеющий активно откликаться на потребности социума, развиваться в продуктивной деятельности и общении, умеющий профессионально организовывать процесс взаимодействия людей, нацеленный на созидание в социокультурном пространстве. Таким образом наша задача, создать необходимые условия и факторы для успешного становления молодежи. А.М.Егорычев обозначает основные условия, определяющие эффективность деятельности всех социальных институтов и структур российского государства и общества, в своём органичном единстве, способных обеспечивать процесс эффективного формирования российского поколения $[3,4]$.

Общество ожидает социально-активную молодежь и поэтому важно находить новые резервы, способные обеспечить личностное развитие молодых людей, имеющих ценностные ориентиры и социально значимые приоритеты в своей жизнедеятельности.

Высшие учебные заведения выступают значимым фактором самореализации молодежи, в связи с тем, что формируют, развивают, транслируют позитивный опыт активной личностной самореализации. 3.С.Белова отмечает, что обучение в вузе позволяет не только получить знания, но и преодолеть многие личностные барьеры, победить страх, что в дальнейшем раскроет многие личностные качества обучающегося. Положительным результатам способствуют следующие методы и формы организации взаимодействия: деловые игры, психотренинги, тестирования, так как они нацелены на преодоление страха перед сложной ситуацией в жизни. Выступления на семинарах, диспутах учат жизни, готовят как интеллектуально, так и психически. На занятиях ошибиться не страшно, но ошибки в жизни могут привести к катастрофе [1].

Каждое учебное заведение старается создать комплекс педагогических условий, позволяющих обучающимся максимально полно реализовать себя в учебной и профессиональной сфере. Оренбургским институтом путей сообщения накоплен значительный опыт создания благоприятной атмосферы для самореализации обучающихся. В рамках данной программы в институте проводится ряд мероприятий. Это всевозможные 
акции, конкурсы, проекты, фестивали. Важным направлением является установление партнерских отношений со структурными подразделениями предприятий железнодорожного транспорта, в которых обучающиеся проходят практики, предусмотренные учебными планами, могут выполнять совместные научно-исследовательские работы, проекты. Что позволяет обучающимся реализовать профессионально-личностный потенциал $[5,6]$.

При выборе технологий, возникает ряд вопросов, на которые необходимо найти ответы. Конечно, хотелось бы подобрать технологию, содержащую минимальное количество инструментария, но позволяющая получить в результате ощутимый эффект. Исследования, которые мы провели позволяет сделать вывод, что устанавливается взаимосвязь между выбранными преподавателем средствами взаимодействия и личностными установками обучающихся. Так как наше исследование направлено на профессиональную самореализацию обучающихся, то и особенность технологий состоит в возможности использования их обучающимися в будущей профессиональной сфере железнодорожного транспорта.

Самореализация молодежи продуктивно осуществляется в том случае, если: востребована активная, позитивная деятельность, успешно реализуется креативный компонент личности молодых людей, обеспечивается успешность как результат достижений, осуществляется развитие и трансляция прогрессивных идей.

Процесс самореализации преподавателя и студента позволяет каждому выступать в роли автора - разработчика идеи, процесса, технологии, пользователя, транслятора опыта, достижений, технологий.

Выбор максимально эффективных форм взаимодействия происходил на основе опыта каждого субъекта деятельности. Проанализированы научные труды отечественных и зарубежных педагогов, психологов. Рассмотрен опыт самореализации молодежи в других сферах деятельности.

Рассматривая проблему профессиональной самореализации молодежи можно выделить следующие способы самореализации: когнитивные, креативные, праксиологические. Вне зависимости от способа самореализации важно обеспечить личностно-развивающее пространство в рамках образовательного процесса вуза.

Образовательным учреждениям необходимо предлагать обучающимся различные способы и формы самореализации, которые бы позволили осуществить поиск индивидуальной траектории самореализации.

Приоритетным направлением в данном случае выступает выстраивание тесной взаимосвязи с предприятиями железнодорожной отрасли. Нацеливая выпускников на трудоустройство на предприятия железнодорожного транспорта и самореализацию в профессиональной сфере.

Обучающиеся Оренбургского института путей сообщения входят в Совет председателей первичных профсоюзных организаций Оренбургского филиала ДОРПРОФЖЕЛ ЮУЖД, что позволяет участвовать в совместных массовых мероприятиях, смотрах-конкурсах, проходить обучение профактива.

Помимо уже ставшими классическими методами обучения, практикуются новые направления обучения - корпоративные тренинги по темам:

- «Лидер в отрасли»;

- «Деловое общение»;

- «Уверенность в себе» и др.

Проводятся информационные встречи со студентами на молодежных форумах и слетах. Местом встречи железнодорожников являются Музеи трудовой и воинской славы железнодорожников. Студенты постоянно занимают места в региональных и муниципальных конкурсах «Золотая молодежь Оренбуржья». 
Обучающиеся Оренбургского института путей сообщения являются кадровым потенциалом железнодорожного транспорта региона. Опыт совместного творчества позволяет будущим специалистам принимать активное участие в корпоративных инновационных проектах: «Новое звено», «Сеть 3Д: Дорога, Дом, Друзья», «Команда 2030», направленных на организационное и техническое перевооружение отрасли.

Систематически проводятся встречи с ветеранами Совета ветеранов Оренбургского региона Южно-Уральской железной дороги. Ветераны активно выступаю на собраниях и встречах, участвуют в проведении технических занятий, планерках.

Среди факторов самореализации личности выделяют внутренние и внешние. К внутренним относят природные способности, самосознание, ценности и т.д. К внешним относят влияние социальных институтов - семья, ближайшее окружение и т.д. Становление человека происходит благодаря совокупному воздействию перечисленных факторов.

Профессиональная самореализация осуществляется в том случае, если востребована личностная активность обучающегося, деятельность носит креативный характер, обеспечивается успешность как результат достижений, осуществляется развитие и реализация прогрессивных идей [7].

Е.Н. Шутенко считает, что использование современных информационных технологий в образовательный процесс призвано усилить и приумножить возможности студентов для обретения опыта самоизменений, для облегчения перехода внешнего содержания во внутреннее с последующей экспликацией в деятельности. В этой связи, пространством применения данных технологий становится не только сфера дидактических программ и методик, но также и область проявлений различных форм самореализации студентов [8].

Стоит отметить, что профессиональной самореализации осуществляется длительно во времени, может проходить сквозь всю жизнь человека. Если говорить в комплексе, то под профессиональным развитием личности понимается рост, становление, интеграция в профессиональном труде личностных качеств и способностей, профессиональных знаний и умений, качественное преобразование личностью своего внутреннего мира, приводящее к принципиально новому его строю и способу жизнедеятельности - творческой самореализации в профессии [9].

Опираясь на классификацию типов и уровней самоопределения самореализации в профессии Н.С. Пряжникова [10], а также проведенной опытно-экспериментальной работой выделим типы и уровни самореализации обучающихся в профессии инженера путей сообщения:

- самоопределение при исполнении конкретных трудовых функциях;

- самоопределение при выполнении трудовых операций, возможность самореализации расширяется, но границы деятельности не позволяют полноценно проявить себя и самореализоваться;

- самореализация в пределах специальности, в данном случае человек может выбирать организации - структурные подразделения предприятий железнодорожного транспорта;

- самоопределение дает возможность специалисту реализовать себя в сопредельных специальностях;

- жизненное самоопределение, выбор жизненного пути, профессия в данном случае будет являться средством или образом жизни;

- личностное самоопределение выступает важным фактором в формировании смысложизненных ориентаций.

В данном исследовании нами была проведена работа по определению мотивов самореализации личности. В анкетировании приняли участие 120 студентов очной формы обучения 1-5 курсов, специальности 23.05.03 Подвижной состав железных дорог. При 
проведении анализа анкетирования получили следующие результаты: среди мотивов самореализации студентов смогли выделить наиболее встречающиеся результаты:

- признание и уважение в группе;

- обладать крепким здоровьем, быть сильным;

- стать интеллектуально развитым специалистом;

- стать успешным в учебе, спорте, жизни

- сделать карьеру, иметь престижную профессию, высокооплачиваемую работу;

- избавиться от вредных привычек, зависимостей

Профессиональная самореализация рассматривается нами достаточно широко и не ограничивается только непосредственной профессиональной деятельностью. А.М.Климанов рассматривает профессиональную самореализацию личности как формирование профессиональной компетентности в определенной области деятельности, готовность к постоянному профессиональному развитию и расширению сферы компетенции в соответствии с мотивами и потребностями личности профессионала [11]. Анализ европейского опыта позволяет сделать вывод о том, что педагоги также находятся в поиске новых форм и методов формирования компетенций. Так R.Schneider, J. Wildt предлагают уровневую модель формирования компетенций, заключающуюся в вовлечении обучающихся в исследовательскую деятельность [12,13].

Одним из факторов, влияющих на самореализацию студента являются ценностные ориентации. А.Н.Николаев разработал авторскую методику по определению ценностных ориентаций и возможностях самореализации [14]. Задача образовательного учреждения в данном случае состоит в выявлении ценностный ориентации студентов и выстраивание совместной работы в вовлечении в совместную деятельность, направленную на профессиональную самореализацию. Немаловажную роль в данном случае играет имидж преподавателя как социокультурный компонент. Педагогические знания и опыт преподавателя направлены на создание ситуации успеха студента в профессиональной самореализации [15-19].

Процесс формирования успешной профессиональной самореализации будущих инженеров путей сообщения осуществляется на основе системы следующих принципов: принцип направленности обучения на формирование готовности к профессиональной самореализации; принципы научности, систематичности и последовательности обучения; принцип сочетания различных методов, форм и средств обучения; принцип активности и самостоятельности обучающихся как субъектов учебной деятельности; - принцип интерактивности между субъектами образовательного процесса, согласно которому обеспечивается субъект - субъектное взаимодействие участников процесса обучения на основе сотрудничества [20-22].

Комплекс педагогических условий включает в себя актуализацию у студентов идеи профессиональной самореализации; выработку социально-психологической установки на профессиональную самореализацию личности; направленность личности на развитие субъектных и личностных характеристик обучающихся [23-25].

Одной из задач нашего исследования выступало исследование сфер самореализации обучающихся нашего института. Экспериментальная работа проводилась в 2017-2020 учебные года. В работе приняли участие студенты факультета высшего образования 1,2,3 курсов очной формы обучения специальностей 23.05.03 Подвижной состав железных дорог, 23.05.04 Эксплуатация железных дорог, 23.05.05 Системы обеспечения движения поездов, 23.05.06 Строительство железных дорог, мостов и транспортных тоннелей Оренбургского института путей сообщения. В исследовании приняли участие 58 студентов. Результаты анализа сфер самореализации, которые выделяют студенты, представим в виде таблицы (Табл.1). 
Сферы самореализации студентов технического вуза

\begin{tabular}{|c|c|c|c|c|}
\hline \multirow{2}{*}{} & Название & \multicolumn{3}{|c|}{ Значимость/ } \\
& & \multicolumn{3}{|c|}{ Частота повторения } \\
\cline { 2 - 5 } & Уурс & 2 курс & 3 курс \\
\hline 1 & Учебная сфера & 22 & 18 & 17 \\
\hline 2 & Научно-исследовательская сфера & 5 & 12 & 14 \\
\hline 3 & Профессиональная сфера & 2 & 5 & 9 \\
\hline 4 & Общественная (политическая) \\
& сфера & 10 & 8 & 4 \\
\hline 5 & Увлечения (хобби) & 8 & 5 & 4 \\
\hline 6 & Семья (личные отношения) & 7 & 6 & 7 \\
\hline 7 & Спортивная сфера & 4 & 4 & 3 \\
\hline
\end{tabular}

Данные результаты говорят о смене приоритетов самореализации студентов по мере обучения в вузе. На первом курсе преобладает учебная сфера, на втором курсе увеличивается число студентов занятых научно-исследовательской работой и к третьему курсу виден рост студентов интересующихся профессиональной сферой. Полученные результаты объясняются тем, что сменяются жизненные приоритеты по мере взросления и переориентацию на профессиональную сферу ближе к получению диплома. На наш взгляд, период 2 курса для студентов является достаточно сложным и «опасным», так прошла адаптация к вузовской жизни, переход к профессиональной деятельности отдален, поэтому считаем необходим комплекс мер со стороны профессорско-преподавательского состава, особенно куратора групп по вовлечению студентов в научно-исследовательскую деятельность.

Таким образом, педагогическое сопровождение обучающихся железнодорожного вуза является одним из ключевых ресурсов по вовлечению в научно-исследовательскую и далее в профессиональную сферу. Основная цель педагогического сопровождения будущих инженеров состоит в формировании свойств и качеств личности, способствующих повышению эффективности профессиональной самореализации.

\section{Литература:}

1. Белова 3.С. Значение образования в процессе самореализации личности // Вестник Ассоциации ВУЗов туризма и сервиса. - 2013. - № 3. - С. 69-73. URL: https://elibrary.ru/item.asp?id=20177697

2. Кормакова В.Н. Влияние социокультурной среды вуза на учебнопрофессиональную самореализацию студентов // Фундаментальные исследования. - 2013. № 8-5. - C. 1198-1202. URL: https://elibrary.ru/item.asp?id=20139072

3. Егорычев А.М. Социальная среда как фактор, определяющий социальное здоровье несовершеннолетних // Профилактика зависимостей. - 2018. - № 4 (16). - С. 191 197. URL:https://elibrary.ru/item.asp?id=37165982

4. Егорычев А.М., Кретинин А.С. Образовательное пространство человека и его базовые характеристики // ЦИТИСЭ. - $\quad 2015$. URL:https://elibrary.ru/item.asp?id=24952318

5. Егорова Ю.Н., Синкина Е.В., Зотова Т.А., Генварева Ю.А. Профессиональная адаптация инженеров путей сообщения // ЦИТИСЭ. - 2019. - № 1 (18). - C. 14. URL: https://elibrary.ru/item.asp?id=37292587

6. Егорова Ю.Н., Синкина Е.В., Зотова Т.А., Генварева Ю.А. Формирование общекультурных компетенций будущего инженера путей сообщения при изучении 
общеобразовательных дисциплин // Мир науки, культуры, образования. - 2019. - № 1 (74). C. 32-34. URL: https://elibrary.ru/item.asp?id=37247271

7. Абульханова-Славская К.А. Стратегия жизни /К.А. Абульханова-Славская. М.: Мысль, 1991. - 299 с. URL: https://elibrary.ru/item.asp?id=21663750

8. Шутенко Е.Н. Концепция самореализации студенческой молодежи в условиях информатизации вузовской подготовки // Образование и саморазвитие. - 2015. - № 4 (46). C. 9-15. URL: https://elibrary.ru/item.asp?id=25337244.

9. Ангеловский А. А. Профессиональное развитие личности: психологопедагогические и социально-философские факторы становления профессионала // Известия Самарского научного центра РАН. - 2011. - №2-3. - C.512-521. URL: https://elibrary.ru/item.asp?id=17304947

10. Пряжников Н.С. Профессиональное и личностное самоопределение /Н.С.Пряжников. - Воронеж: НПО «МОДЭК», 1996. - 256 с. URL: https://elibrary.ru/item.asp?id=26550461

11. Климанов А.М. Этапы становления теории профессиональной самореализации как компонента профессиональной успешности // Педагогика и современность. - 2016. № 2 (22). C. - 74-80. URL: https://elibrary.ru/item.asp?id=26009452

12. Schneider R. Kompetenzentwicklung durch Forschendes Lernen? // Journal Hochschuldidaktik. - 2009. - № 2. - P. 33-37.

13. Schneider R., Wildt J. Forschendes Lernen in Praxisstudien - Ein hochschuldidaktisches Konzept zur Förderung professioneller Kompetenzen in der Lehrerbildung // Journal Hochschuldidaktik. - 2007. - № 2. - P. 11-15.

14. Николаев А.Н. Ценностные ориентации как фактор представлений молодежи о возможностях самореализации // Вестник Псковского государственного университета. Серия: Психолого-педагогические науки. - 2015. - № 2 . - C. 229-233. URL: https://elibrary.ru/item.asp?id=25715513

15. Попова О.И. Имидж преподавателя: проблема самореализации в образовательном взаимодействии // Педагогическое образование в России. — 2011 — № 4. - C. 224-232. URL: https://elibrary.ru/item.asp?id=17051982

16. Саркисьян Т.Н., Яблонская Л. В. Имидж преподавателя как социокультурный компонент// Общество: философия, история, культура. - 2016. - № 3. — С. 96-99. URL: https://elibrary.ru/item.asp?id=25673248

17. Соломахина Т.А. Коммуникативные универсальные учебные действия как фактор саморазвития и самореализации личности // Приоритетные научные направления: от теории к практике. - 2016. - № 24-1. - C. 137-142. URL: https://elibrary.ru/item.asp?id=25730990.

18. Селезнева Е.В. Самоотношение и самореализация в структуре акмеологического развития человека // Мир психологии. - 2016. - № 1 (85). - С. 249-261. URL: https://elibrary.ru/item.asp?id=26599402

19. Сысоева Е. Ю. Рефлексивный анализ имидж-образующих характеристик преподавателя вуза// Азимут научных исследований: педагогика и психология. — 2017. - Т. 6. — № 4(21). — C. 209-213. URL: https://elibrary.ru/item.asp?id=32283597

20. Манакина Е.М. Профессиональная самореализация студентов в контексте реформирования системы российского профессионального образования // Среднее профессиональное образование. - 2017. - № 6. - C. 5-10. URL: https://elibrary.ru/item.asp?id=29862024.

21. Немова Я.С. Профессионально-творческая самореализация личности как категория профессиональной успешности в образовании // Вестник науки и образования. 2019. - № 15 (69). - C. 86-88. URL: https://elibrary.ru/item.asp?id=39184340. 
22. Киенко Е.В., Морозова И.С. Специфика самореализации личности в профессиональной деятельности // Вестник Кемеровского государственного университета. 2010. - № 3 (43). - C. 69-78. URL: https://elibrary.ru/item.asp?id=15166239.

23. Митюшникова А.А., Наличникова И.А. Межкультурная коммуникация в профессиональной подготовке специалистов // Молодежная наука в XXI веке: традиции, инновации, векторы развития: материалы междунар. науч.-исслед. конф.: Самарский государственный университет путей сообщения, Оренбургский институт путей сообщения филиал, 2017. - C. 33-36. URL: https://elibrary.ru/item.asp?id=30037514

24. Чернов Ю.В., Наличникова И.А. Коммуникативная компетенция в профессиональной подготовке железнодорожника // Молодежная наука в XXI веке: традиции, инновации, векторы развития: материалы междунар. науч.-исслед. конф.: Самарский государственный университет путей сообщения, Оренбургский институт путей сообщения - филиал, 2017. - C. 74-75. URL: https://elibrary.ru/item.asp?id=30037517

25. Егорова Ю.Н., Генварева Ю.А. Факторы и риски успешной самореализации студента в образовательном пространстве вуза. - Уфа: "Аэтерна", 2016. - С. 61-76. URL: https://elibrary.ru/item.asp?id=25990792

\section{References:}

1. Belova Z.S. The importance of education in the process of personal self-realization. Bulletin of the Association of Universities of Tourism and Service, 2013, no. 3. pp, 69-73. (In Russian) URL: https://elibrary.ru/item.asp?id=20177697

2. Kormakova V.N. The influence of the sociocultural environment of the university on the educational and professional self-realization of students. Fundamental Research, 2013, no. 8-5, pp. 1198-1202. (In Russian) URL: https://elibrary.ru/item.asp?id=20139072

3. Egorychev A. M. The social environment as a factor determining the social health of minors. Prevention of addictions, 2018, no. 4 (16), pp. 191-197. (In Russian) URL:https://elibrary.ru/item.asp?id=37165982

4. Egorychev A.M., Kretinin A.S. Human educational space and its basic characteristics. CITISE, 2015, no. 3. (In Russian) URL:https://elibrary.ru/item.asp?id=24952318

5. Egorova Yu.N., Sinkina E.V., Zotova T.A., Genvareva Yu.A. Professional adaptation of communication engineers. CITISE, 2019, no. 1 (18), pp. 14. (In Russian) URL: https://elibrary.ru/item.asp?id=37292587

6. Egorova Yu.N., Sinkina E.V., Zotova T.A., Genvareva Yu.A. The formation of the general cultural competencies of the future engineer of communications during the study of general educational disciplines. World of science, culture, education, 2019, no. 1 (74), pp. 32-34. (In Russian)URL: https://elibrary.ru/item.asp?id=37247271.

7. Abulkhanova-Slavskaya K.A. Life Strategy. Moscow, Thought Publ., 1991, 299 p. (In Russian) URL: https://elibrary.ru/item.asp?id=21663750

8. Shutenko E.N. The concept of student self-actualization in the conditions of informatization of university training. Education and self-development, 2015, no. 4 (46), pp. 9-15. (In Russian) URL: https://elibrary.ru/item.asp?id=25337244

9. Angelovsky A. A. Professional development of personality: psychological, pedagogical and socio-philosophical factors of becoming a professional. Bulletin of the Samara Scientific Center of the Russian Academy of Sciences, 2011, no. 2-3, pp.512-521. (In Russian) URL: https://elibrary.ru/item.asp?id=17304947

10. Pryazhnikov N.S. Professional and personal self-determination. Voronezh, NPO MODEK Publ., 1996, 256 p. (In Russian) URL: https://elibrary.ru/item.asp?id=26550461 
11. Klimanov A.M. Stages of the theory of professional self-realization as a component of professional success. Pedagogy and modernity, 2016, no. 2 (22), pp. 74-80. (In Russian) URL: https://elibrary.ru/item.asp?id=26009452

12. Schneider R. Kompetenzentwicklung durch Forschendes Lernen? Journal Hochschuldidaktik, 2009, no. 2, pp. 33-37. (In Germany)

13. Schneider R., Wildt J. Forschendes Lernen in Praxisstudien - Ein hochschuldidaktisches Konzept zur Förderung professioneller Kompetenzen in der Lehrerbildung. Journal Hochschuldidaktik, 2007, no. 2, pp. 11-15. (In Germany)

14. Nikolaev A.N. Value orientations as a factor in young people's ideas about the possibilities of self-realization. Bulletin of the Pskov State University. Series: Psychological and Pedagogical Sciences, 2015, no. 2, pp. 229-233. (In Russian) URL: https://elibrary.ru/item.asp?id=25715513

15. Popova O.I. The image of a teacher: the problem of self-realization in educational interaction. Pedagogical education in Russia, 2011, no. 4, pp. 224-232. (In Russian) URL: https://elibrary.ru/item.asp?id=17051982

16. Sargsyan T.N., Yablonskaya L.V. The image of a teacher as a sociocultural component. Society: philosophy, history, culture, 2016, no. 3, pp. 96-99. (In Russian) URL: https://elibrary.ru/item.asp?id=25673248

17. Solomakhina T.A. Communicative universal educational actions as a factor of selfdevelopment and self-realization of a person. Priority research areas: from theory to practice. 2016. no. 24-1. pp. 137-142. URL: https://elibrary.ru/item.asp?id=25730990. (In Russian)

18. Selezneva E.V. Self-relation and self-realization in the structure of human acmeological development. World of Psychology, 2016, no. 1 (85), pp. 249-261. (In Russian) URL: https://elibrary.ru/item.asp?id=26599402

19. Sysoeva E. Yu. Reflexive analysis of image-forming characteristics of a university teacher. Azimuth of scientific research: pedagogy and psychology, 2017, vol. 6, no. 4 (21), pp. 209213. (In Russian) URL: https://elibrary.ru/item.asp?id=32283597

20. Manakina E.M. Professional self-realization of students in the context of reforming the system of Russian vocational education. Secondary vocational education, 2017, no. 6, pp. 5-10. (In Russian) URL: https://elibrary.ru/item.asp?id=29862024.

21. Nemova Ya.S. Professional and creative self-realization of a personality as a category of professional success in education. Bulletin of science and education, 2019, no 15 (69), pp. 86-88. (In Russian) URL: https://elibrary.ru/item.asp?id=39184340

22. Kienko E.V., Morozova I.S. The specifics of personal self-realization in professional activities. Bulletin of the Kemerovo State University, 2010, no. 3 (43), pp. 69-78. (In Russian) URL: https://elibrary.ru/item.asp?id=15166239

23. Mityushnikova A.A., Nalichnikova I.A. Intercultural communication in the training of specialists. Samara State University of Railways, Orenburg Institute of Railways Publ., 2017, pp. 33-36. (In Russian) URL: https://elibrary.ru/item.asp?id=30037514

24. Chernov Yu.V., Nalichnikova I.A. Communicative competence in vocational training of a railway worker. Samara State University of Railways, Orenburg Institute of Railways Publ., 2017, pp. 74-75. (In Russian) URL: https://elibrary.ru/item.asp?id=30037517

25. Egorova Yu.N., Genvareva Yu.A. Factors and risks of successful student selfrealization in the educational space of the university. Ufa, Aeterna Publ., 2016, pp. 61-76. (In Russian) URL: https://elibrary.ru/item.asp?id=25990792

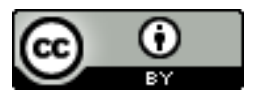

